\title{
The significance of phosphate source in the preparation of functional luminescent phosphate materials
}

\author{
Minsung KIM, Makoto KOBAYASHI, Hideki KATO and Masato KAKIHANA ${ }^{\dagger}$ \\ Institute of Multidisciplinary Research for Advanced Materials, Tohoku University, \\ 2-1-1 Katahira, Aoba-ku, Sendai 980-8577, Japan
}

The stability and reactivity of phosphate raw materials, including two water-soluble phosphates, ethylene glycol-conjugated phosphate (EG-P), and polyethylene glycol-conjugated phosphate (PEG-P) developed by our group, were examined with the aim of synthesizing phosphates with high functionalities. EG-P was found to gradually hydrolyze in an aqueous solution, resulting in the formation of $\mathrm{H}_{3} \mathrm{PO}_{4}$, while PEG-P was stable for more than two months. EG-P and PEG-P did not form insoluble materials in aqueous solution in the presence of many other cations, while precipitates were often observed using conventional phosphate raw materials. In particular, there were no precipitates in an aqueous solution of PEG-P in the presence of $\mathrm{Ca}^{2+}$ and $\mathrm{Li}^{+}$ions, which easily formed insoluble phosphates in a given aqueous condition. Consequently, single-phase $\mathrm{LiCaPO}_{4}$ with high luminescence properties could be obtained by a polymerizable complex method employing PEG-P, while impurity phases were formed using other $\mathrm{P}$ sources, and $\mathrm{KSrPO}_{4}$ was formed as a single phase using EG-P and PEG-P.

(02014 The Ceramic Society of Japan. All rights reserved.

Key-words : Phosphate, Raw material, Solution-based method, Phosphor, Homogeneity

[Received February 15, 2014; Accepted June 11, 2014]

\section{Introduction}

Phosphate-based compounds are recognized as an important functional material group in various application fields such as biotechnology, electric engineering, and energy technology, ${ }^{1)-3)}$ owing to their diverse functionalities. Various kinds of approaches can be employed in the synthesis of inorganic phosphate compounds. ${ }^{4)-6)}$ Among them, solution-based method such as combustion, hydrothermal, co-precipitation, sol-gel, and polymerizable complex (PC) methods yield high performance phosphates. ${ }^{7), 8)}$ However, in the synthesis of multi-component phosphates using solution-based methods, there is one critical limitation that is lack of proper phosphorus sources. $\mathrm{H}_{3} \mathrm{PO}_{4}$ and $\mathrm{NH}_{4} \mathrm{H}_{2} \mathrm{PO}_{4}$, which are conventional $\mathrm{P}$ sources, have high reactivity with other cations, and undesirable precipitates are easily formed in an aqueous solution in the presence of other cations. ${ }^{9)}$ Consequently, the final compounds show low performance owing to poor homogeneity and formation of impurity phases. Previous reports have demonstrated that such undesirable precipitates formed from reactions between phosphates and cations could be prevented by the use of condensed chain-structured phosphates. ${ }^{10), 11)}$ Recently, we have reported the synthesis of an ethylene glycol-conjugated phosphate (EG-P) and a polyethylene glycol-conjugated phosphate (PEG-P) as a P source. At the same time, we have succeeded in the improvement of luminescence properties of $\mathrm{Eu}^{2+}$-activated phosphate phosphors via the PC method employing EG-P and PEG-P. ${ }^{12), 13)}$

There is a growing interest in synthesis of various phosphate compounds via the PC method employing developed P sources. As described above, the nature of phosphorus raw material intended for use is directly linked to properties of the final

\footnotetext{
Corresponding author: M. Kakihana; E-mail: kakihana@tagen. tohoku.ac.jp

* Preface for this article: Dol http://dx.doi.org/10.2109/jcersj2.122.P8-1
}

materials for the synthesis of phosphates through solution-based methods. Therefore, an examination of the stability and reactivity of phosphorus raw materials is rather important to meet this growing interest. In the present study, the stability of the developed $\mathrm{P}$ sources in water was investigated by ${ }^{31} \mathrm{P}\left\{{ }^{1} \mathrm{H}\right\} \mathrm{NMR}$ analysis. The reactivity between the phosphate sources including conventional $\mathrm{P}$ sources and several cations under aqueous conditions was investigated to confirm the applicability of elements for each $\mathrm{P}$ source in a solution-based method. The relationship between the reactivity of $\mathrm{P}$ sources and properties of the final products was compared by the synthesis of $\mathrm{Eu}^{2+}$-activated phosphors via the PC method using the P sources.

\section{Experimental procedures}

2.1 Preparation and evaluation of hydrolysis behavior of EG-P and PEG-P

EG-P was synthesized using phosphoric acid and ethylene glycol by a reflux process at $393 \mathrm{~K}$ for $24 \mathrm{~h}$. PEG-P was synthesized by the reaction among polyphosphoric acid, phosphorus pentoxide, and polyethylene glycol 300. Details of the preparation procedures of EG-P and PEG-P are described elsewhere. ${ }^{12), 13)}$ The synthesized gel-like EG-P and PEG-P were dissolved in distilled water and set to $1.0 \mathrm{M}$ as a $\mathrm{P}$ source for analysis of hydrolysis behavior. After the solutions containing EG-P or PEG-P were kept under ambient conditions for 2 and 8 weeks, they were dried under vacuum at room temperature. The obtained gel-like substances were dissolved in $\mathrm{D}_{2} \mathrm{O}$ and $\mathrm{pH}$ was adjusted to 13 using $10 \mathrm{M} \mathrm{NaOH}$ to prepare a solution for NMR analysis. ${ }^{31} \mathrm{P}\left\{{ }^{1} \mathrm{H}\right\}$ NMR spectra were recorded on a $400 \mathrm{MHz}$ NMR spectrometer for ${ }^{1} \mathrm{H}$ resonance (Bruker Co.; AVANCE400).

2.2 Evaluation of reactivity of phosphorus sources $20 \mathrm{ml}$ of aqueous solutions of metals including $\mathrm{Li}, \mathrm{Na}, \mathrm{K}, \mathrm{Mg}$, $\mathrm{Ca}, \mathrm{Sr}, \mathrm{Ba}, \mathrm{Y}, \mathrm{Ce}, \mathrm{Eu}$ (>99\%, Kanto Chemical Co., Inc.), Rb, Fe, and $\mathrm{La}$ (>99\% Wako Pure Chemical Ltd.) were prepared. The 
cation concentration in each solution was set to $0.25 \mathrm{M} .10 \mathrm{ml}$ of $0.5 \mathrm{M} \mathrm{NH}_{4} \mathrm{H}_{2} \mathrm{PO}_{4}$ (99\%, Kanto Chemical Co., Inc.), $\mathrm{H}_{3} \mathrm{PO}_{4}$ (85\%, Kanto Chemical Co., Ltd.), and EG-P, or PEG-P were added into the metal solutions. When a precipitate was visually observed after stirring, the combination was designated as being "reactive".

\subsection{Synthesis of phosphates}

$3 \mathrm{~mol} \% \mathrm{Eu}^{2+}$-doped $\mathrm{KSrPO}_{4}$ and $\mathrm{LiCaPO}_{4}$ phosphors were synthesized via the $\mathrm{PC}$ method employing each of the various $\mathrm{P}$ sources. Details of the synthesis procedure has been previously reported. ${ }^{12), 13)}$ Here, the synthesis procedures are briefly described. $\mathrm{LiNO}_{3}, \mathrm{Ca}\left(\mathrm{NO}_{3}\right)_{2} \cdot 4 \mathrm{H}_{2} \mathrm{O}$, and $\mathrm{Eu}\left(\mathrm{NO}_{3}\right)_{3}$ were dissolved in a citric acid aqueous solution. The mixture was first heated at $353 \mathrm{~K}$ for $2 \mathrm{~h}$ to allow chelation, and then, PEG-P and propylene glycol were added into the resulting solution. The temperature was subsequently increased to $423 \mathrm{~K}$ to promote gel formation. The formed gel was heated at $1123 \mathrm{~K}$ in air to remove the organic content. The formed powder was reduced at $1373 \mathrm{~K}$ for $3 \mathrm{~h}$ and subsequently at $1073 \mathrm{~K}$ for $18 \mathrm{~h}$ in an $\mathrm{Ar} / 4 \% \mathrm{H}_{2}$ atmosphere for $3 \mathrm{~h}$. The samples were characterized by powder X-ray diffraction (XRD, Brucker Co.; D2 PHASER) using $\mathrm{Cu} \mathrm{K} \alpha$ radiation. Excitation and emission spectra of the phosphors were recorded using a fluorescence spectrometer (Hitachi, Ltd.; F-4500) at room temperature.

\section{Results and discussion}

Figure 1 shows ${ }^{31} \mathrm{P}\left\{{ }^{1} \mathrm{H}\right\}$ NMR spectra of the prepared EG-P and PEG-P. The ratio of contents could be calculated from the integrations of each peak. The total yield of mono-, di-, and triesters in the EG-P was $59.4 \%$, while the $\mathrm{H}_{3} \mathrm{PO}_{4}$ content was $40.6 \%$. Small peaks located near the main ester peaks could be assigned to esters with different molecular weights, in which an EG molecule conjugated to $\mathrm{P}$ was connected to another EG through unreacted $\mathrm{OH}^{14)}$ It is therefore considered that EG-P contained esters with various chemical structures. The PEG-P consisted of a $72.5 \%$ monoester, $10.1 \%$ diester, and $17.4 \% \mathrm{H}_{3} \mathrm{PO}_{4}$ composition. No peaks were observed around the peaks assigned to esters for PEG-P, indicating that the mono- and diesters have only one corresponding chemical structure in the PEG-P.

Table 1 summarizes the ratio of $\mathrm{H}_{3} \mathrm{PO}_{4}$ and esters in EG-P and PEG-P aqueous solutions calculated from ${ }^{31} \mathrm{P}\left\{{ }^{1} \mathrm{H}\right\}$ NMR spectra after those solutions were kept for 2 and 8 weeks at room temperature. The ratio of contents in the as-prepared EG-P and PEG-P is also shown. The stability and hydrolysis behaviors of

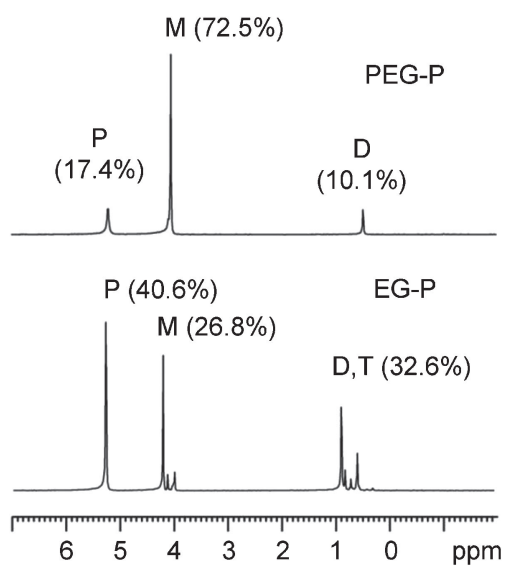

Fig. 1. ${ }^{31} \mathrm{P}\left\{{ }^{1} \mathrm{H}\right\}$ NMR spectra of as-prepared EG-P and PEG-P in $\mathrm{D}_{2} \mathrm{O}$ at $\mathrm{pH} 13\left(\mathrm{P}=\mathrm{H}_{3} \mathrm{PO}_{4}, \mathrm{M}, \mathrm{D}, \mathrm{T}=\right.$ mono-, di-, triesters, respectively). each solution were evaluated by analysis of the content ratios at a given holding time, because the esters would possibly be transformed into $\mathrm{H}_{3} \mathrm{PO}_{4}$ by hydrolysis in these time periods. In case of the EG-P, the di- and triesters were converted into monoesters in the aqueous solution due to their hydrolysis, which was noted by the increase in monoester proportion from 26.8 to $29.3 \%$ after 2 weeks. At the same time, the monoesters were hydrolyzed to $\mathrm{H}_{3} \mathrm{PO}_{4}$; accordingly, the proportion of $\mathrm{H}_{3} \mathrm{PO}_{4}$ to esters increased to $45.2 \%$ from the initial value of $40.6 \%$ over the two-weeks time period. Hydrolysis was observed to continue with time, yielding an increase proportion $(52.2 \%)$ of $\mathrm{H}_{3} \mathrm{PO}_{4}$ to esters after 8 weeks. On the other hand, the amounts of $\mathrm{H}_{3} \mathrm{PO}_{4}$, monoester, and diester in the aqueous solution of PEG-P were not significantly changed even after 8 weeks. These results indicated that the PEG-P was highly stable under the aqueous conditions. It has been reported that degradation of such esters is strongly dependent on the molecular weight. ${ }^{15)}$ For example, an oligomer with low molecular weight is easily degraded, while a polymer with high molecular weight shows good stability over longer periods. Therefore, the EG-P showed a more pronounced hydrolysis behavior due to its oligomeric structure, while the PEG-P with a polymeric structure showed greater stability.

The construction of an "element library" compiling the reactivity between $\mathrm{P}$ sources and cations is important to clarify applicable compounds as potential $\mathrm{P}$ sources for functional materials. Table 2 shows the results of observations when $\mathrm{P}$ sources including $\mathrm{NH}_{4} \mathrm{H}_{2} \mathrm{PO}_{4}, \mathrm{H}_{3} \mathrm{PO}_{4}$, EG-P, and PEG-P were combined with various cations under aqueous conditions at $323 \mathrm{~K}$ for 1 week. Irrespective of the $\mathrm{P}$ sources, there were no precipitates using $\mathrm{Na}, \mathrm{K}$, and $\mathrm{Rb}$ salts, and white precipitates were observed in solutions containing $\mathrm{Mg}$ and $\mathrm{Ce}$. $\mathrm{NH}_{4} \mathrm{H}_{2} \mathrm{PO}_{4}$ and $\mathrm{H}_{3} \mathrm{PO}_{4}$ showed rapid precipitation with almost all metals. A precipitate

Table 1. Proportion of $\mathrm{H}_{3} \mathrm{PO}_{4}$ and esters in as-prepared EG-P and PEG$\mathrm{P}$ and in aqueous solutions of EG-P and PEG-P after keeping over 2 and 8 weeks at room temperature

\begin{tabular}{cccccccc}
\hline \multirow{2}{*}{$\begin{array}{c}\text { Time } \\
\text { (weeks) }\end{array}$} & \multicolumn{5}{c}{ Ratio in product (\%) } \\
\cline { 2 - 4 } \cline { 2 - 4 } \cline { 5 - 7 } & $\mathrm{P}$ & $\mathrm{M}$ & $\mathrm{D}, \mathrm{T}$ & & $\mathrm{P}$ & $\mathrm{M}$ & $\mathrm{D}$ \\
\hline 0 & 40.6 & 26.8 & 32.6 & & 17.4 & 72.5 & 10.1 \\
2 & 45.2 & 29.3 & 25.5 & & 16.9 & 71.3 & 11.8 \\
8 & 52.2 & 37.1 & 10.7 & & 15.4 & 71.8 & 12.8 \\
\hline
\end{tabular}

$* \mathrm{P}=\mathrm{H}_{3} \mathrm{PO}_{4}, \mathrm{M}=$ monoester, $\mathrm{D}=$ diester, $\mathrm{T}=$ triester

Table 2. Reactivity between $\mathrm{P}$ sources and cations under aqueous condition ( $\mathrm{P}=$ precipitate was observed, $\mathrm{N}=$ a very small amount of precipitates was observed, $\times=$ no precipitates were observed)

\begin{tabular}{ccccc}
\hline Element & $\mathrm{NH}_{4} \mathrm{H}_{2} \mathrm{PO}_{4}$ & $\mathrm{H}_{3} \mathrm{PO}_{4}$ & EG-P & PEG-P \\
\hline $\mathrm{Li}$ & $\mathrm{P}$ & $\mathrm{P}$ & $\mathrm{P}$ & $\times$ \\
$\mathrm{Na}$ & $\times$ & $\times$ & $\times$ & $\times$ \\
$\mathrm{K}$ & $\times$ & $\times$ & $\times$ & $\times$ \\
$\mathrm{Rb}$ & $\times$ & $\times$ & $\times$ & $\times$ \\
$\mathrm{Mg}$ & $\mathrm{P}$ & $\mathrm{P}$ & $\mathrm{P}$ & $\mathrm{P}$ \\
$\mathrm{Ca}$ & $\mathrm{P}$ & $\mathrm{P}$ & $\mathrm{P}$ & $\times$ \\
$\mathrm{Sr}$ & $\mathrm{P}$ & $\mathrm{P}$ & $\mathrm{N}$ & $\times$ \\
$\mathrm{Ba}$ & $\mathrm{P}$ & $\mathrm{P}$ & $\mathrm{N}$ & $\times$ \\
$\mathrm{Y}$ & $\mathrm{P}$ & $\mathrm{P}$ & $\mathrm{P}$ & $\times$ \\
$\mathrm{La}$ & $\mathrm{P}$ & $\mathrm{P}$ & $\mathrm{P}$ & $\times$ \\
$\mathrm{Ce}$ & $\mathrm{P}$ & $\mathrm{P}$ & $\mathrm{P}$ & $\mathrm{P}$ \\
$\mathrm{Eu}$ & $\mathrm{P}$ & $\mathrm{P}$ & $\times$ & $\times$ \\
$\mathrm{Fe}$ & $\mathrm{P}$ & $\times$ & $\times$ & $\times$ \\
\hline
\end{tabular}




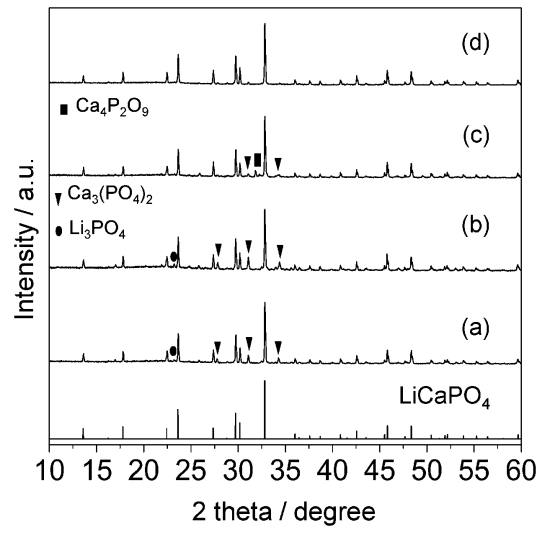

Fig. 2. XRD patterns of the samples synthesized by the $\mathrm{PC}$ method using (a) $\mathrm{NH}_{4} \mathrm{H}_{2} \mathrm{PO}_{4}$, (b) $\mathrm{H}_{3} \mathrm{PO}_{4}$, (c) EG-P, and (d) PEG-P.

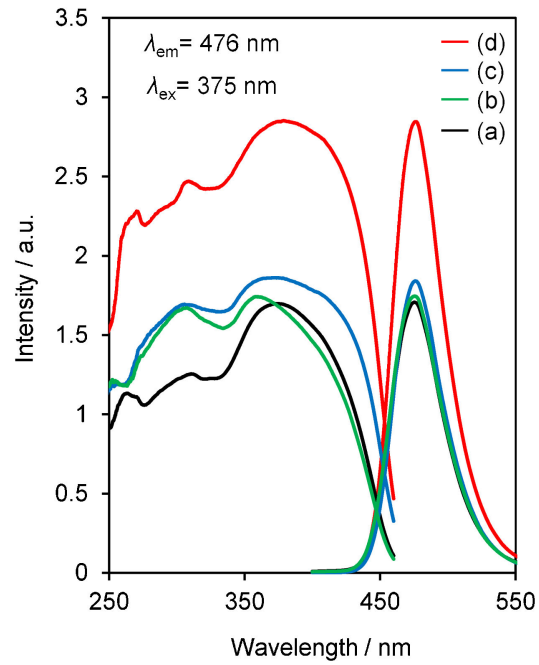

Fig. 3. Excitation and emission spectra of $3 \mathrm{~mol} \% \mathrm{Eu}^{2+}$-doped samples synthesized by the $\mathrm{PC}$ method using (a) $\mathrm{NH}_{4} \mathrm{H}_{2} \mathrm{PO}_{4}$, (b) $\mathrm{H}_{3} \mathrm{PO}_{4}$, (c) EG-P, and (d) PEG-P.

between $\mathrm{Fe}$ and $\mathrm{NH}_{4} \mathrm{H}_{2} \mathrm{PO}_{4}$ was observed, while other $\mathrm{P}$ sources were stable and did not react with Fe. EG-P reacted with $\mathrm{Li}, \mathrm{Ca}$, $\mathrm{Sr}$, and $\mathrm{Ba}$, however, the precipitates formed with $\mathrm{Sr}$ or $\mathrm{Ba}$ were negligible. Therefore, the EG-P could be used as a P source in the synthesis of phosphate compounds excluding $\mathrm{Li}, \mathrm{Mg}, \mathrm{Ca}, \mathrm{Y}, \mathrm{La}$, and Ce. On the other hand, the PEG-P did not form precipitates under aqueous conditions in the presence of almost all cations tested. It was speculated that the proportions of $\mathrm{H}_{3} \mathrm{PO}_{4}$ and the hydrolysis behaviors of $\mathrm{P}$ sources affected their stabilities in solutions containing cations. Even though PEG-P showed precipitates with $\mathrm{Mg}$ and $\mathrm{Ce}$, it was considered to be a desirable $\mathrm{P}$ source for the PC method.

Figures 2 and 3 show the XRD patterns and photoluminescence spectra of $\mathrm{Eu}^{2+}$-activated $\mathrm{LiCaPO}_{4}$ synthesized by the PC method employing (a) $\mathrm{NH}_{4} \mathrm{H}_{2} \mathrm{PO}_{4}$, (b) $\mathrm{H}_{3} \mathrm{PO}_{4}$, (c) EG-P, and (d) PEG-P. The synthesis of $\mathrm{LiCaPO}_{4}$ with the precise stoichiometry is difficult to achieve by solution-based methods because of the high reactivity of $\mathrm{Li}$ and $\mathrm{Ca}$ with $\mathrm{P}$ sources under aqueous conditions. Nevertheless, the sample synthesized by the PC method employing PEG-P consisted of a single-phase $\mathrm{LiCaPO}_{4}$ [Fig. 2(d)]. In contrast, impurities such as $\mathrm{Li}_{3} \mathrm{PO}_{4}, \mathrm{Ca}_{3}\left(\mathrm{PO}_{4}\right)_{2}$, and $\mathrm{Ca}_{4} \mathrm{P}_{2} \mathrm{O}_{9}$ were formed when $\mathrm{NH}_{4} \mathrm{H}_{2} \mathrm{PO}_{4}, \mathrm{H}_{3} \mathrm{PO}_{4}$, and EG-P were used [Figs. 2(a)-2(c)]. As confirmed in Table 2, Li and

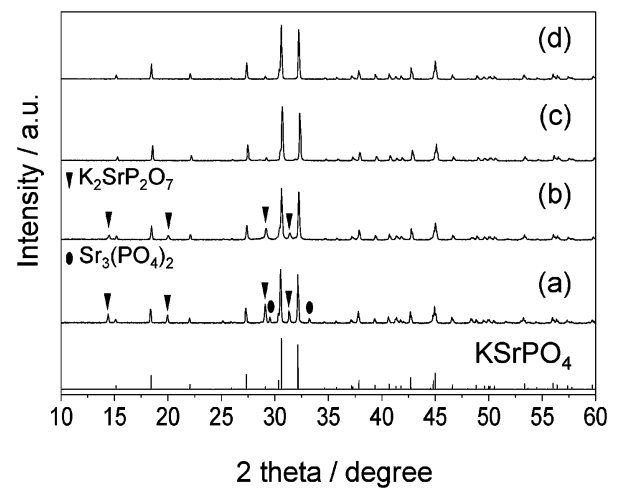

Fig. S1. XRD patterns of $\mathrm{Eu}^{2+}$-activated $\mathrm{KSrPO}_{4}$ synthesized by the PC method using (a) $\mathrm{NH}_{4} \mathrm{H}_{2} \mathrm{PO}_{4}$, (b) $\mathrm{H}_{3} \mathrm{PO}_{4}$, (c) EG-P, and (d) PEG-P.

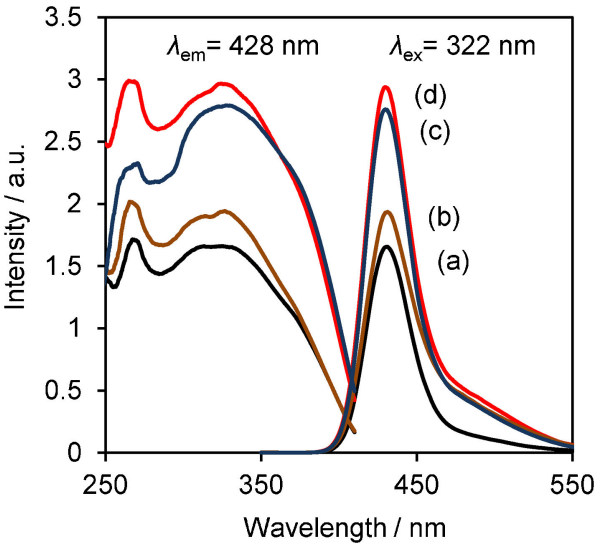

Fig. S2. Excitation and emission spectra of $3 \mathrm{~mol} \% \mathrm{Eu}^{2+}$-doped $\mathrm{KSrPO}_{4}$ powders synthesized by the $\mathrm{PC}$ method using (a) $\mathrm{NH}_{4} \mathrm{H}_{2} \mathrm{PO}_{4}$, (b) $\mathrm{H}_{3} \mathrm{PO}_{4}$, (c) EG-P, and (d) PEG-P.

Ca formed precipitates with $\mathrm{NH}_{4} \mathrm{H}_{2} \mathrm{PO}_{4}, \mathrm{H}_{3} \mathrm{PO}_{4}$, and EG-P in aqueous solutions. In fact, during the synthesis, white precipitates were observed using $\mathrm{NH}_{4} \mathrm{H}_{2} \mathrm{PO}_{4}, \mathrm{H}_{3} \mathrm{PO}_{4}$, and EG-P, while no precipitates was observed using PEG-P. The undesirable precipitates consist of agglomerations of specific elements and prevent constituents from homogeneously distributing at the atomic level. Distribution of a tiny amount of a rare-earth ion in a phosphor material is quite important, since it is directly connected to its performance. Consequently, only PEG-P allowed us to synthesize single-phase $\mathrm{LiCaPO}_{4}$; moreover, the sample exhibited the highest emission intensity compared with other samples (Fig. 3). Previously, we reported that EG-P was applicable for the synthesis of a highly homogeneous $\mathrm{KSrPO}_{4}: \mathrm{Eu}^{2+}$ phosphor via the $\mathrm{PC}$ method. ${ }^{12)} \mathrm{KSrPO}_{4}: \mathrm{Eu}^{2+}$ with almost the same properties could be obtained using PEG-P, while the samples synthesized using $\mathrm{H}_{3} \mathrm{PO}_{4}$ and $\mathrm{NH}_{4} \mathrm{H}_{2} \mathrm{PO}_{4}$ contained impurities and had low emission properties (Figs. S1, S2). Considering Table 1, the results are quite reasonable since both EG-P and PEG-P rarely react with $\mathrm{K}$ and $\mathrm{Sr}$ ions. Thus, the choice of a proper $\mathrm{P}$ source in the synthesis of phosphates following the compiled "element library" is quite useful.

\section{Conclusion}

The stabilities and reactivities of EG-P and PEG-P were compared with those of conventional P sources. It was confirmed that the EG-P was gradually hydrolyzed under aqueous conditions with a continual increase in the proportion of $\mathrm{H}_{3} \mathrm{PO}_{4}$, 
while PEG-P did not show hydrolysis behavior, even after 8 weeks. Because $\mathrm{NH}_{4} \mathrm{H}_{2} \mathrm{PO}_{4}$ and $\mathrm{H}_{3} \mathrm{PO}_{4}$ both showed rapid precipitation with almost all cations in solution, they were limited in their use in solution-based methods. EG-P is considered to be a suitable $\mathrm{P}$ source in solution-based methods except for compositions including $\mathrm{Li}, \mathrm{Ca}, \mathrm{Mg}$, or $\mathrm{Ce}$. PEG-P formed precipitates in the presence of $\mathrm{Ce}$ or $\mathrm{Mg}$; furthermore, $\mathrm{PEG}-\mathrm{P}$ was the only $\mathrm{P}$ source suitable for the synthesis of a single-phase $\mathrm{LiCaPO}_{4}: \mathrm{Eu}^{2+}$ phosphor with high emission intensity. These results are in good agreement with the results of the element library constructed in the present study.

Acknowledgments This work was partially supported by a Grant-in-Aid for Scientific Research on Innovative Areas of "Fusion Materials: Creative Development of Materials and Exploration of Their Function through Molecular Control" (No. 2206) from the Ministry of Education, Culture, Sports, Science and Technology, Japan (MEXT) and a Grant-in-Aid for JSPS Fellows (24.9285) from the Japan Society for the Promotion of Science (JSPS).

\section{References}

1) L. L. Hench, J. Am. Ceram. Soc., 74, 1487-1510 (1991).

2) W. Jiayuan, S. Zechang and W. Xuezhe, Proc. 5th Int. IEEE Veh. Power Propul. Conf. (VPPC 09'), Sept 7-11, Michigan, USA, (2009) pp. 1657-1661.
3) S. H. M. Poort, W. Janssen and G. Blasse, J. Alloys Compd., 260, 93-97 (1997).

4) D. Jugović and D. Uskoković, J. Power Sources, 190, 538-544 (2009).

5) J. K. Han, J. I. Choi, A. Piquette, M. Hannah, M. Anc, M. Galvez, J. B. Talbot and J. McKittrick, ECS J. Solid State Sci. Technol., 2, R3138-R3147 (2012).

6) Y. K. Su, Y. M. Peng, R. Y. Yang and J. L. Chen, Opt. Mater, 34, 1598-1602 (2012).

7) M. Kakihana, J. Ceram. Soc. Japan, 117, 857-862 (2009).

8) M. Kakihana, J. Sol-Gel Sci. Technol., 6, 7-55 (1996).

9) W. Weng, L. Huang and G. Han, Appl. Organomet. Chem., 13, 555-564 (1999).

10) J. R. Van Wazer and C. F. Callis, Chem. Rev., 58, 1011-1046 (1958).

11) F. Rashchi and J. A. Finch, Miner. Eng., 13, 1019-1035 (2000).

12) M. Kim, M. Kobayashi, H. Kato and M. Kakihana, J. Mater. Chem. C, 1, 5741-5746 (2013).

13) M. Kim, M. Kobayashi, H. Kato and M. Kakihana, Opt. Photonics J., 3, 13-18 (2013).

14) J. Pretula, K. Kaluzynski, B. Wisniewski, R. Szymanski, T. Loontjens and S. Penczek, J. Polym. Sci. A Polym. Chem., 46, 830-843 (2008).

15) M. J. Roberts, M. D. Bentley and J. M. Harris, Adv. Drug Deliv. Rev., 64, 116-127 (2012). 